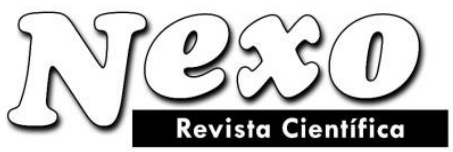

\title{
EDITORIAL UNI
}

\author{
Uriel Cardoza Sánchez ${ }^{1}$
}

En este 2021, segundo año de la Pandemia, la edición y publicación de artículos científicos en las revistas de la UNI, ha tenido un amplio crecimiento, lo cual se ve reflejado en lo siguiente:

La Revista Higo de la sede UNI Norte, ha publicado 13 artículos en sus dos números del volumen 11 , con 7 autores de nuestra comunidad universitaria y 6 autores externos nacionales. Felicitamos por el trabajo realizado su editora la Dra. Alba Veranay Diaz.

La Revista Arquitectura + de la Facultad de Arquitectura UNI Central, está por publicar el segundo número del volumen 6 , habiendo publicado 5 artículos en su primer número de este año, con contenido de dos autores nacionales y tres internacionales en representación de Colombia y México, por lo que igualmente felicitamos de sobremanera al Arq. Gabriel Obando, editor de dicha revista.

Dato importante en destacar es que por ser de las primeras 14 revistas de Nicaragua en estar Indexadas en el Catálogo 2.0 de Latindex Higo y Arquitectura +, ambas publicaciones recibieron reconocimientos en el marco del Segundo Festival Nacional de Publicaciones Educativas donde sus editores tuvieron la oportunidad de compartir las buenas prácticas en relación a los espacios de visibilidad que tienen las nuevas revistas científicas de las universidades e identificar nuevos retos para la-proyección nacional e internacional.

En el segundo trimestre del año la Revista Nexo Científica lanzó el número especial en honor al 50 Aniversario de la carrera de Ingeniería Química, conteniendo 8 artículos tanto en inglés como en español, agradeciendo de forma muy especial, la trascendental gestión de la Facultad de Ingeniería Química FIQ a través del Ing. Rodolfo Espinoza, resaltándose el trabajo realizado en este primer número especial.

En la perspectiva de diversificar los autores y los contenidos de Nexo Revista Científica, se ha dado continuidad a la publicación de números especiales por áreas estratégicas académicas de nuestra institución; en este caso el área de Diseño, Construcción, Urbanismo y Territorio, en alianza estratégica con directivos de la Unión de Escuelas y Facultades de América Latina, UDEFAL, para convocar desde Nexo Revista Científica y publicar un segundo número especial en adherencia al conjunto de actividades relativas al 60 aniversario de la Conferencia Latinoamericana de Escuelas y Facultades de Arquitectura, CLEFA, que tuvo su último evento presencial en el año 2018 en Concepción Chile, estando aún pendientes de llevar a cabo la XVIII CLEFA que se realizaría en la Facultad de Arquitectura de la Universidad Nacional de México, UNAM, Ciudad México, pero por motivos de evento pandémico de connotación planetaria no se pudo llevar a cabo.

Este segundo número especial que hoy presentamos, contiene un total de (7) artículos de autores nicaragüenses y de otros países de Latinoamérica como Guatemala, Colombia, y México con filiación española y panameña, con lo que se logra el objetivo de tener una publicación científica de alta calidad para conmemorar tan importante evento de la UDEFAL, en la espera de poder

\footnotetext{
${ }^{1}$ Director de Investigación, UNI.
} 
volver a encontrarnos presencialmente. En este sentido agradecemos el apoyo del Master Arq. Elmer González Cavallo, secretario general de UDEFAL y del Dr. Arq. Alfredo Otero, director de investigación de UDEFAL, quien a su vez ha actuado como Editor Invitado de este número especial.

Nexo de Igual forma está a las puertas de publicar su segundo número regular No. 6 del volumen 34, donde tendremos 30 artículos provenientes de autores de México, Perú, Nicaragua, Cuba y Rusia, por lo que agradecemos y reconocemos el arduo trabajo editorial del Dr. Róger Sánchez para asegura la gestión de todos los manuscritos publicados.

Es importante señalar que recientemente los editores y equipo técnico de nuestras revistas recibió capacitación de parte los administradores del Portal de Revistas de Nicaragua, para la debida instalación de la plataforma Open Journal Systems (OJS) en los servidores de la UNI, y así poner en línea el portal de revistas de la nuestra Alma Mater, trabajo técnico que ha asumido el Ing. Noel Pavón, garantizando todos los requerimientos técnicos necesarios para que los editores de las revistas científicas de la UNI puedan gestionar el contenido de cada una de las mismas.

En conclusión, podemos afirmar que el 2021 ha sido un año más que provechoso en el desarrollo de nuestras revistas científicas, no solo en cuanto a contenido y periodicidad, sino también al respecto del soporte técnico que se requiere para adecuada gestion editorial. 